\title{
A survey of various intelligent home applications using IoT and intelligent controllers
}

\author{
Mustafa Asaad Omran, Wasaan Kadhim Saad, Bashar Jabbar Hamza, Ahmed Fahem Al-baghdadi \\ Engineering Technical Collage-Najaf, Al-Furat Al-Awsat Technical University, Iraq
}

\begin{tabular}{l} 
Article Info \\
\hline Article history: \\
Received Apr 21, 2021 \\
Revised Jun 10, 2021 \\
Accepted Jun 18, 2021 \\
\hline
\end{tabular}

\section{Keywords:}

Communication protocols

Intelligent

Intelligent home

Internet of things

Smart home

\begin{abstract}
The tremendous development in technology used in our daily life was one of the most important incentives for researchers to add technology that is easy to use and useful in human life, an example internet of things (IoT) and systems of intelligence used in various fields. This article provides an overview of the smart home ( $\mathrm{SH}$ ) study of the Internet of Things as smart homes (SHs) have attracted great interest with communication technology advancements. The intelligent home is an Internet of Things technology that allows the monitoring and control of devices via the Internet using a home automation system (HAS). Followed by the justification for choosing the smart home and smart home engineering, and what are the most used communication protocols for smart homes, whether wired or wireless.
\end{abstract}

This is an open access article under the CC BY-SA license.

\section{Corresponding Author:}

Mustafa Asaad Omran

Engineering Technical Collage-Najaf

Al-Furat Al-Awsat Technical University, Najaf, Iraq

Email: mustafa.asaad@student.atu.edu.iq; coj.bash@atu.edu.iq

\section{INTRODUCTION}

Internet of things ( IoT) can be used in diverse fields [1], in the more productive industries [2], the smart home and smart cities [3]-[6], smart energy [7]-[9], vehicular communications [10], [11], intelligent farming [12], [13], intelligent interconnection of university buildings, logistics, and health care [14], [15]. The IoT enables the communication and exchange of data between various physical devices via the Internet.

Nowadays, people live in an internet-connected world with the majority of devices connected to exchange knowledge, consequently the world has come to be like a small town. The recent fast development of several Bluetooth, Wi-Fi, ZigBee, and 6LoWPAN technologies has made it convenient, easy and inexpensive to connect various devices to the Internet. IoT is composed of two sections: The first is the Internet, while the second is things. The Internet is a massive global network comprised of trillions of computers and other electronic devices, which enables users to use certain common protocols to access all information and everyone else on earth. Stuff contribute to communication with every individual. IoT uses a range of technologies, such as radio frequency identification (RFID), sensors, actuators, smartphones and support for computing cloud. By using IoT, People from anywhere can link anything and at any time to get service and information [16], [17].

The intelligent home has been described as a modern all-intelligence app. in residential management and "comfort, healthcare, protection, and energy conservation" [18]. The opinion adopted in this survey paper also indicates that two complementary viewpoints converge on smart home functioning: user-centred and equipment-centred, Based respectively on occupancy comfort and performance of building systems [19]. Throughout the first half of the twentieth century, the consumer approach for intelligent homes began and has 
developed through the generations. The unit or constructing centre view was only achieved by developing ICT and developing intelligent energy infrastructure. In the past decade, the production of modern "intelligent devices capable of being accessed and controlled via remote applications. This network of devices and other products is built into sensors, circuitry, applications and networking.

The Internet of things (IoT) was renamed. In conjunction with a newly developed cloud computing system, it has led to a cloud-centred IoT solution for the development of intelligent home [20]. In recent years, intelligent homes have become more and more sophisticated. These systems have materials and methods for the sharing of knowledge and resources on all forms of appliances [21]. An intelligent home is an IoT domain that provides electronic, sensor, software and network access to a physical device network within a house.

Intelligent households are computerized systems with built-in monitoring and control devices, an example ventilation, heating, air conditioning and lighting. Modern networks with switches and transmitters with the central axis are also known as "gateways." Control systems, which provide a user interface and communicate with a smartphone, cell phone or computer; IoT manages network connectivity [22], [23].

Many smart homes (SHs) are available commercially and classified systems were classified into two broad categories: those that operated locally and those that operated remotely [24]. Users can monitor their home automation equipment with the help of a domestic controller equipped with both stationary and wireless communication technology (Zigbee, Bluetooth, and global system for mobile communication (GSM)). Users can monitor their homes remotely via the internet via their personal computers or mobile devices in the second group. However, the design of such automation systems involves a range of issues and should be considered.

The smart home must provide an easy-to-use interface to easily and efficiently install, track and manage home appliances. Furthermore, the automation device should be quick enough and provide a suitable data rate and a safe communication range, because these things are among the problems facing the $\mathrm{SH}$ to know the full potential of wireless technology [25]. The following are the seven parts of this paper: Section 1 provides a general description of the relevant works. Section 2 defines intelligent home and intelligence, why the intelligent home should be chosen, and smart home architecture. Section 3 discusses communication protocols and an overview of wired and wireless communication protocols. Section 4 talks about motivations for studying the intelligent home for the IoT. Section 5 is an overview of the challenges facing smart homes. Section 6 explains recommendations for the user to enhance acceptance and usage of SH app. Section 7 concludes with the conclusions of this study.

\section{RELATED WORK}

In the future, the internet of things is expected to take on an unusual pattern. This segment deals with previously conducted studies on $\mathrm{SH}$ in the context of the internet of things, a wide range of SH-based research. This study findings and recommendations help to clarify SH's advanced privacy practices and It is summarized in Table 1.

Table 1. Summary of the smart home systems

\begin{tabular}{|c|c|c|c|c|c|c|c|c|c|c|c|}
\hline 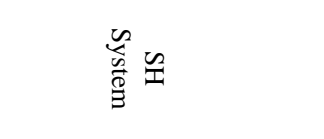 & $\frac{\Omega}{\stackrel{0}{\Xi}}$ & $\begin{array}{l}\Omega \Xi \\
\varrho \\
\stackrel{0}{0} \\
\stackrel{0}{0}\end{array}$ & 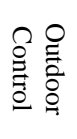 & 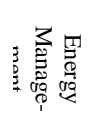 & 畓 & 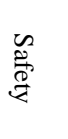 & $\begin{array}{l}\mathscr{\mathscr { D }} \\
\stackrel{\Xi}{\Xi} \\
\Xi\end{array}$ & 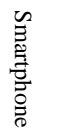 & 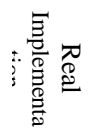 & $\vec{\Omega}$ & 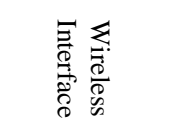 \\
\hline David et al. [26] & Arduino Mega & Yes & Yes & Yes & Yes & Yes & & Yes & & Yes & Bluetooth/WiFi \\
\hline Ozeer et al. [27] & Raspberry Pi & Yes & Yes & Yes & Yes & & & & Yes & Yes & Fog-IoT \\
\hline Jabbar et al. [28] & Arduino Mega & Yes & & & Yes & & & Yes & & & WiFi \\
\hline Davidovic and Labus [29] & Raspberry Pi & Yes & & & Yes & & & Yes & & & Bluetooth/WiFi \\
\hline Kodali and Soratkal [30] & Node MCU & Yes & & & & & & Yes & & Yes & $\mathrm{WiFi}$ \\
\hline Konidala et al. [31] & PC Server & & & & & & Yes & Yes & & & RFID \\
\hline Badabaji and Nagaraju [32] & PC Server & & & & Yes & Yes & & & & Yes & GSM/WiFi \\
\hline Ganesh [33] & $8051 \mu \mathrm{c}$ & Yes & Yes & & & & & & & Yes & GSM \\
\hline Bhat et al. [34] & PC Server & & & Yes & & & Yes & & & & WiFi \\
\hline Gupta and Chhabra [35] & Galileo board & Yes & Yes & Yes & Yes & & Yes & Yes & & Yes & Ethernet \\
\hline Kaur et al. [36] & Arduino & Yes & & Yes & & & Yes & Yes & & & GSM \\
\hline
\end{tabular}

\section{SMART HOME}

This segment offers a summary of intelligent home technologies. It begins with the concepts of SHs, and what is the intelligence of $\mathrm{SH}$, followed by the justification for using smart home, and a general overview of smart homes designs. 


\subsection{Intelligent home description}

The idea of intelligent homes first emerged as a wonderful home efficiency vision of the "homes of tomorrow" in the 1930s [37]. Many promises of 'unprecedented comfort, Relief and complacency and advantages of modern household life have only been accomplished in the last few decades of the last century. At the same time, the focus on domestic efficiency has increased to energy efficiency. Darby [19] describes two key concepts for smart homes: home and user-focused, which defines intelligent houses as very automatic housing of integrated devices, with the emphasis on modern techniques, comfort and (domestic) quality.

Building and system centred in building energy efficiency, auxiliary services and generation of distributed electricity, and how information and communication technology can be used to address them. The author notes that both terms share the significance of communication. for the connection of devices and remote access/control and the provision of services [19]. Figure 1 is an example to illustrate the intelligent home concept.

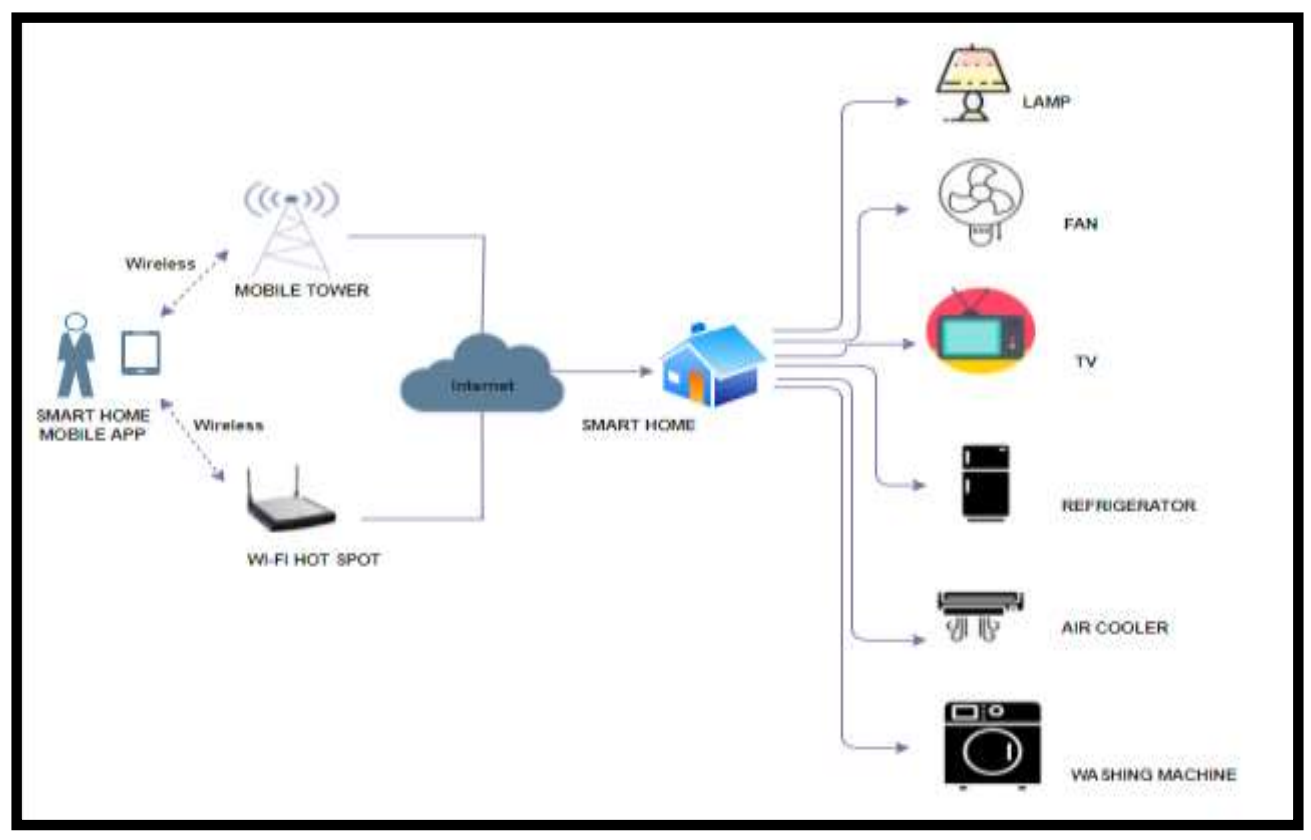

Figure 1. Is an example of the $\mathrm{SH}$ concept

\subsection{What does the intelligence meam?}

When speaking of intelligent houses, one should too think of how to describe "intelligent" or "smart". What distinguishes an intelligent home from a traditional home in which most of us live? Based on Edwards and Grinter [38], smart environments and omnipresent computing intelligence have four features:

a) The environment uses sensor information to assess the current situation (For eg, if you have triggered a motion sensor detector, it means somebody has to get near).

b) The thing can presume state while taking into account a variety of factors at once (e.g. the machine can determine that it is time for dinner if the table includes several persons).

c) By evaluating the situation, the environment will forecast a user's intentions (e.g. if motion detectors are installed in the future, it means that the consumer goes through the corridor and the user will want his or her path illuminated).

d) The environment can behave preventively on the basis of purpose (e.g. the device can opt to switch the lights in advance so that the user may walk easily).

\subsection{Why the SH?}

The integrated illumination control system is one of the advantages of SH. The user no longer needs to turn electrical appliances on or off manually. There are two different choices, for instance, if the person enters the bedroom: either the lighting automatically on and off after user exits the room or the user is able to control the software switch on his smartphone. The light luminosity also may be managed to reduce power consumption. Also, based on sensor readings, users can adjust room conditions (humidity, and temperature) 
such as regulating the fan speed from their mobile app or automatically changing the fan speed according to room temperature. This will help boost energy efficiency because, if the electrical appliances are turned off automatically or readily if they are not used, it decreases energy usage and power bill costs.

The user may also use a smartphone, tablet or computer to control electrical equipment and monitor the house conditions. For instance, if the user forgot about turn off the fan and has entered his office, he can turn off the fan by using his intelligent device. The user can also mount flood sensors, carbon monoxide, smoke, to warn users if their homes are inundated or whether air is unsafe, so they can only sit at home.

The user receives an alert on the phone for a safety system if an incident occurs. If there is an intruder, no need to worry from the owner because the homeowner can monitor the motion sensor from the smartphone and the alarm continues if any motion is detected. The security system is the main element of safeguarding the houses against intruders. By installing wired surveillance cameras to prevent a burglar from entering the house. All intelligent home components, such as air conditioning, ventilation, heating, central illumination, automated devices and a safety system, can offer comfort and protection in everyday life [28].

\subsection{Intelligent home design}

At least a few things, including sensors, equipment or actuators, are in an intelligent home that is not inherently intelligent on its own. A sensor generates data but does not contribute to the value of the home environment on its own. For instance, if the homeowner is needed to change the temperature to external temperature, moisture and other variables, a thermostat is not deemed clever. It can hold the temperature constant, but automation is not "intelligence." Only by collectively storing and analyzing all data on the environment, extracting trends and decisions taken without user interference can an environment be considered intelligent. The design of a smart home is based on how devices communicate, how and where the data from sensors and use patterns are stored, how Knowledge and patterns are interpreted and collected and how the user communicates with the devices and how the devices communicate with the user.

Soliman et al. [39] developed an intelligent home device architecture, actuators and sensors are attached to a microcontroller and are used to gather environmental data and carry out some acts. The data is transmitted from the microcontroller allowed by the ZigBee technology to the central server. The server then uploads the data through an application-programming-interface (API) to the cloud storage. A backend server, Storage and app in the front end are included in the cloud solution. The data is back-end processed and analyzed (Google App Engine). The user is able to view and manage the environment with a web application. The architecture proposed by Cook et al. [40] was made up of controllers (servers for computers), sensors (door/temperature/motion/light sensors), and relays (actuators). The communications layer is Wireless technology-based including ZigBee wireless network. A publish/subscribe pattern is the basis for the middleware layer. Jie et al. [41] suggested an architectural model addressing the scalability problem. The proposed model with a standardized interface allows devices to be connected to or removed with little effort from the intelligent home infrastructure. In [42] Hosek et al. define the Technology and hardware specifications of an intelligent Gateway to Home. Guoqiang et al. [43] suggest an intelligent house portal architecture that can be configured for approved communication protocols and convert Heterogeneous sensor information in a consistent format. Figure 2 shows the general intelligent home architecture.

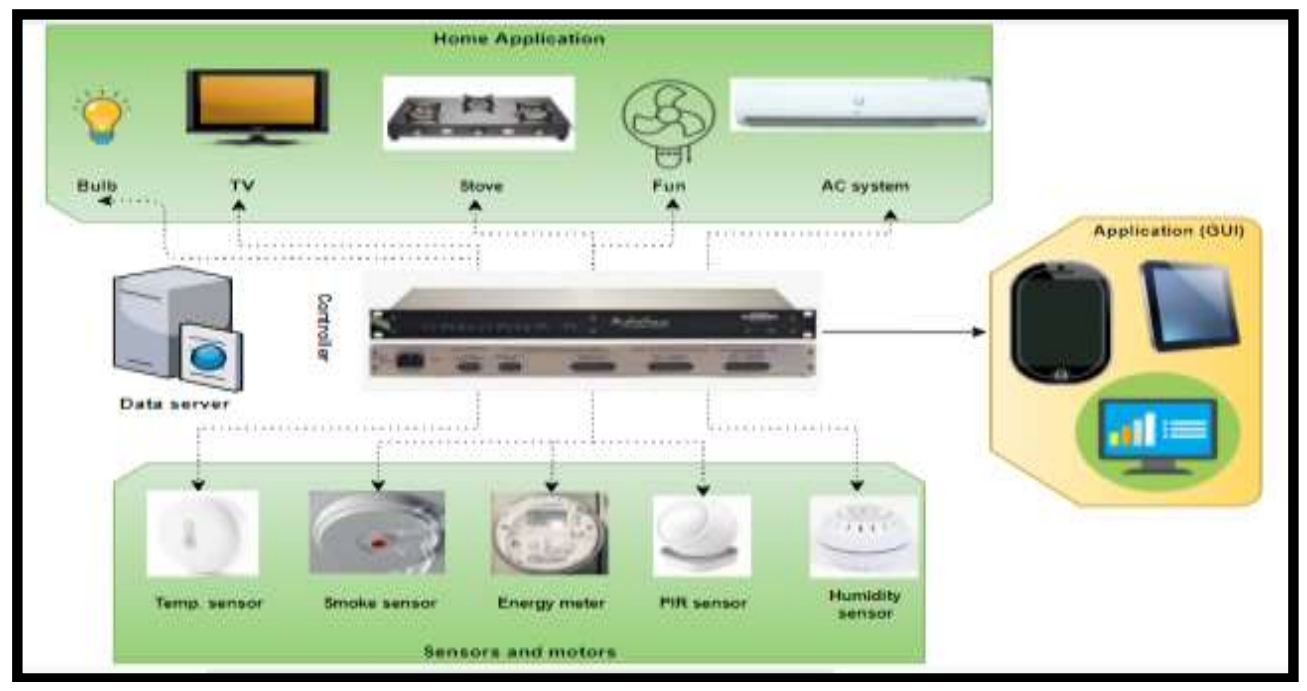

Figure 2. An example of the intelligent home architecture 


\section{PROTOCOLS OF CONNECTIVITY AND COMMUNICATION}

Devices must be linked to share information in an intelligent home environment. Intelligence (as previously stated) occurs when the environment is aware of the system's current state. To accomplish this, a single sensor is insufficient to collect useful data; therefore, multiple sensors are needed to communicate and increase the usefulness of the data gathered. The communication protocols are used to decide how these devices and sensors can interact. These protocols determine how companies and collaborators exchange information with requirements, hardware and licensing protocols. Communication protocols are typically classified into three main media groups: 1) hybrid, 2) wired, and 3) wireless.

Some protocols provide longer distances, while others provide stronger protections, while others reduce energy consumption. The choice is often dependent on the size of the network. Personal area networks (PAN) and local area networks (LAN) are widely used within a smart home body area network (BAN). A comprehensive comparison of multiple home area network (HAN) communication technologies is given in [44]. The remainder of this section offers a summary and recommendations for selecting the most popular and evolving communication technologies (wired and wireless).

\subsection{Wired protocols for communication}

Wired communication involves the information transmission via a wired media. It's one of the earliest methods of data transmission from electronic telegraph was used to send messages.

\begin{tabular}{|c|c|}
\hline Advantages & Disadvantages \\
\hline $\begin{array}{l}\text { 1. Safety: As a connection to a network involves a cable to } \\
\text { physically link the device, it is almost impossible to spy or } \\
\text { tamper from external communication networks. }\end{array}$ & $\begin{array}{l}\text { 1. Mobility: it is not possible to adjust the position of the device when } \\
\text { the cables are installed without rewired or extending the wire. }\end{array}$ \\
\hline $\begin{array}{l}\text { 2. User-friendly: a network connection is as simple as a cable } \\
\text { connection to the device; the correct network doesn't need to } \\
\text { be chosen from the list of entries of networks or passwords, as } \\
\text { with wireless networks. }\end{array}$ & $\begin{array}{l}\text { 2. Power: Wired networks normally require power; when power is cut } \\
\text { off, the network can not operate on a battery in a critical condition, as } \\
\text { the wireless network may. }\end{array}$ \\
\hline $\begin{array}{l}\text { 3. Distance: wired data transfer goes beyond the normal } \\
\text { wireless protocols (Wi-Fi } 802.11 \mathrm{ac} \text { ); issues like interference } \\
\text { or obstacles would not impede the transmission of wire cables } \\
\text { in the encircled media. }\end{array}$ & $\begin{array}{l}\text { 3. Expansion: expanding the wired network coverage is not simpler } \\
\text { than installing a Fresh wireless modem, cabling and external hardware } \\
\text { (hubs) might be required. }\end{array}$ \\
\hline $\begin{array}{l}\text { 4. Data rate: Ethernet potential data rates over } 100 \mathrm{Gbps} \text {, } \\
\text { whereas Wi-Fi } 802.11 \text { ac's maximum theoretical rate is } 1.3 \\
\text { Gbps. }\end{array}$ & $\begin{array}{l}\text { 4. Complexity and Cost: professional works and preparation for the } \\
\text { wired network; when a smart house is constructed, installing a wired } \\
\text { network otherwise running cables through cables will later become a } \\
\text { boring task, and can be a little unpleasant. }\end{array}$ \\
\hline
\end{tabular}

\subsection{Wireless protocols for communication}

Wireless communication does not require sending and receive information via RF signals using wires. Due to easy usage and reduced network configuration setup and implementation costs of new devices, wireless communication protocols are becoming common within SH networks. There are many wireless protocols, Table 2 summarizes the main features of the wireless protocols most commonly used in intelligent homes.

\begin{tabular}{ll}
\hline \multicolumn{1}{c}{ Advantages } & \multicolumn{1}{c}{ Disadvantages } \\
\hline $\begin{array}{l}\text { 1. Mobility: because the connection of a device to a } \\
\text { network requires no physical connection, it is possible to }\end{array}$ & $\begin{array}{l}\text { 1. Protection: Although existing encryption mechanisms are solid, packets } \\
\text { are interceptable, and maybe decrypted (although it may be extremely } \\
\text { move it without losing connectivity; it is also simple to } \\
\text { move the device through another wireless network. }\end{array}$ \\
$\begin{array}{l}\text { configuration if the wireless network is not secured in any way. } \\
\text { 2. Expandability: it is easy to add additional devices to the } \\
\text { network When the maximum approved system number is }\end{array}$ & $\begin{array}{l}\text { Ethernet or MoCA); however, for most smart home applications, data rates } \\
\text { are also adequate in practice. }\end{array}$ \\
not surpassed; it is easy to scale up or down wireless & \\
networks if necessary at no or minimal cost. &
\end{tabular}


Table 2. Wireless protocols of communication

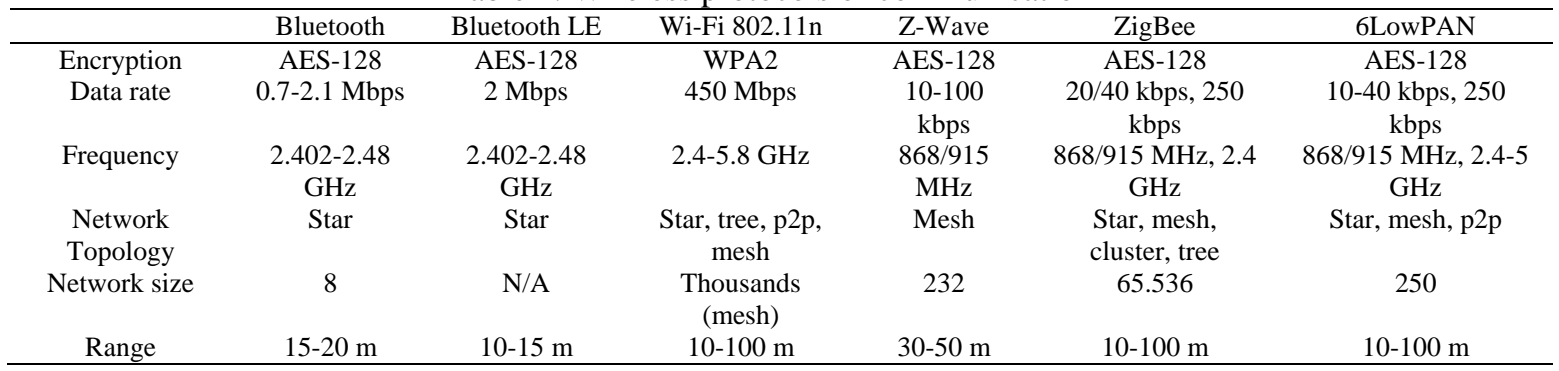

\section{MOTIVATIONS}

The advantages that use intelligent home apps based on clear because energy conservation is critical for both the home and health care, in particular the elderly, and the cost of basic home needs, entertainment and comfort is reduced. The benefits are listed in four categories [45]-[48] in Figure 3 summarizes the most important incentives for studying the smart home.

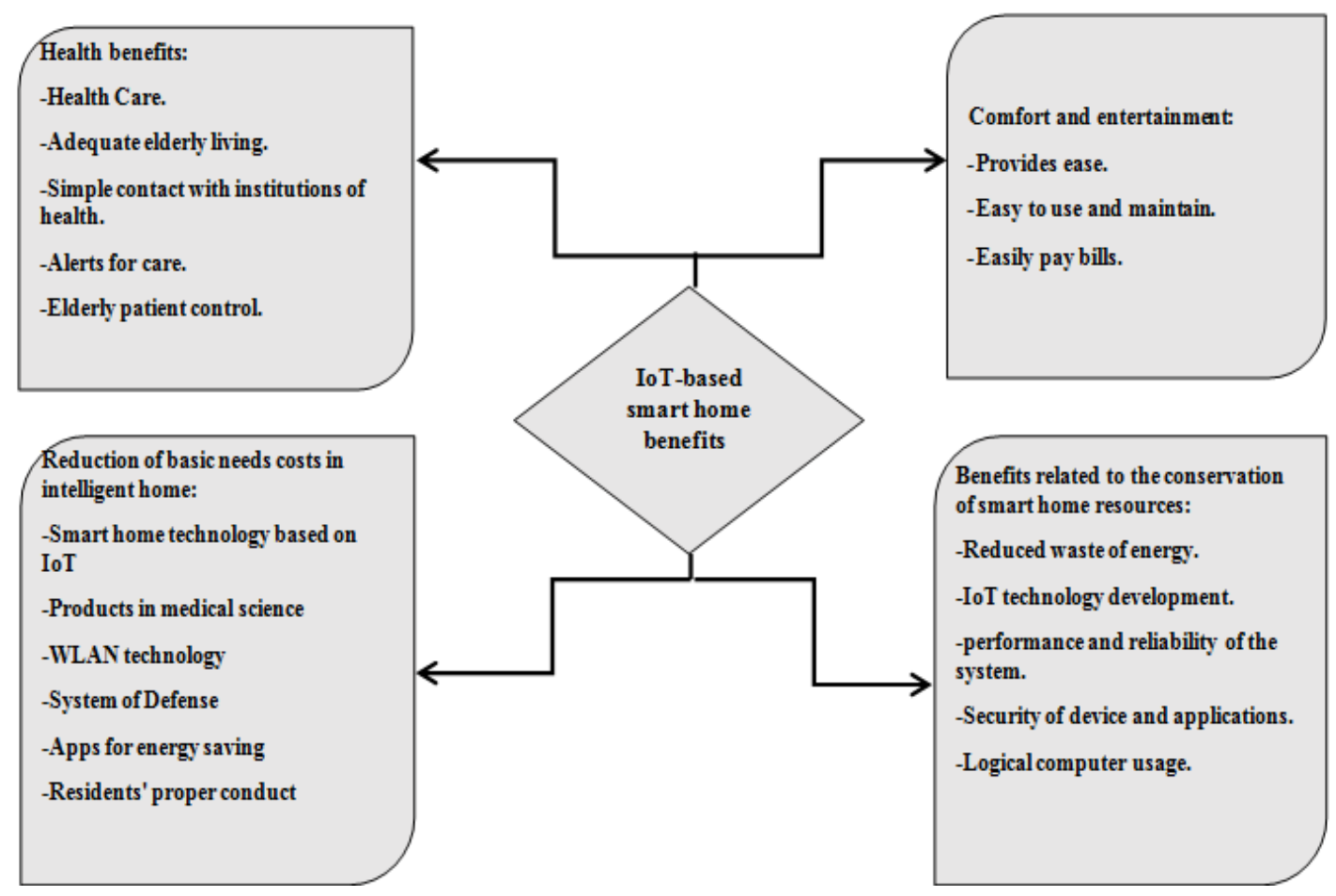

Figure 3. Classifications of advantages of IoT-based intelligent home apps

\section{CHALLENGES}

There are various advantages of the smart way of smart home applications oriented to the Internet of things, however, these systems are not suitable solutions for connecting telecommunication networks. The survey showed that researchers are concerned about the nuances of smart operation in IoT-based SH applications and their use. Users face obstacles to the high cost of smart systems and the difficulty in maintaining them, unfriendly user interfaces, and most users do not take into account safety and security, restrictions on wired and wireless technologies, In addition to the challenges of energy management, data transfer, and healthcare. Figure 4 Summarizes the main obstacles that users face based on the smart home application method [45]. 


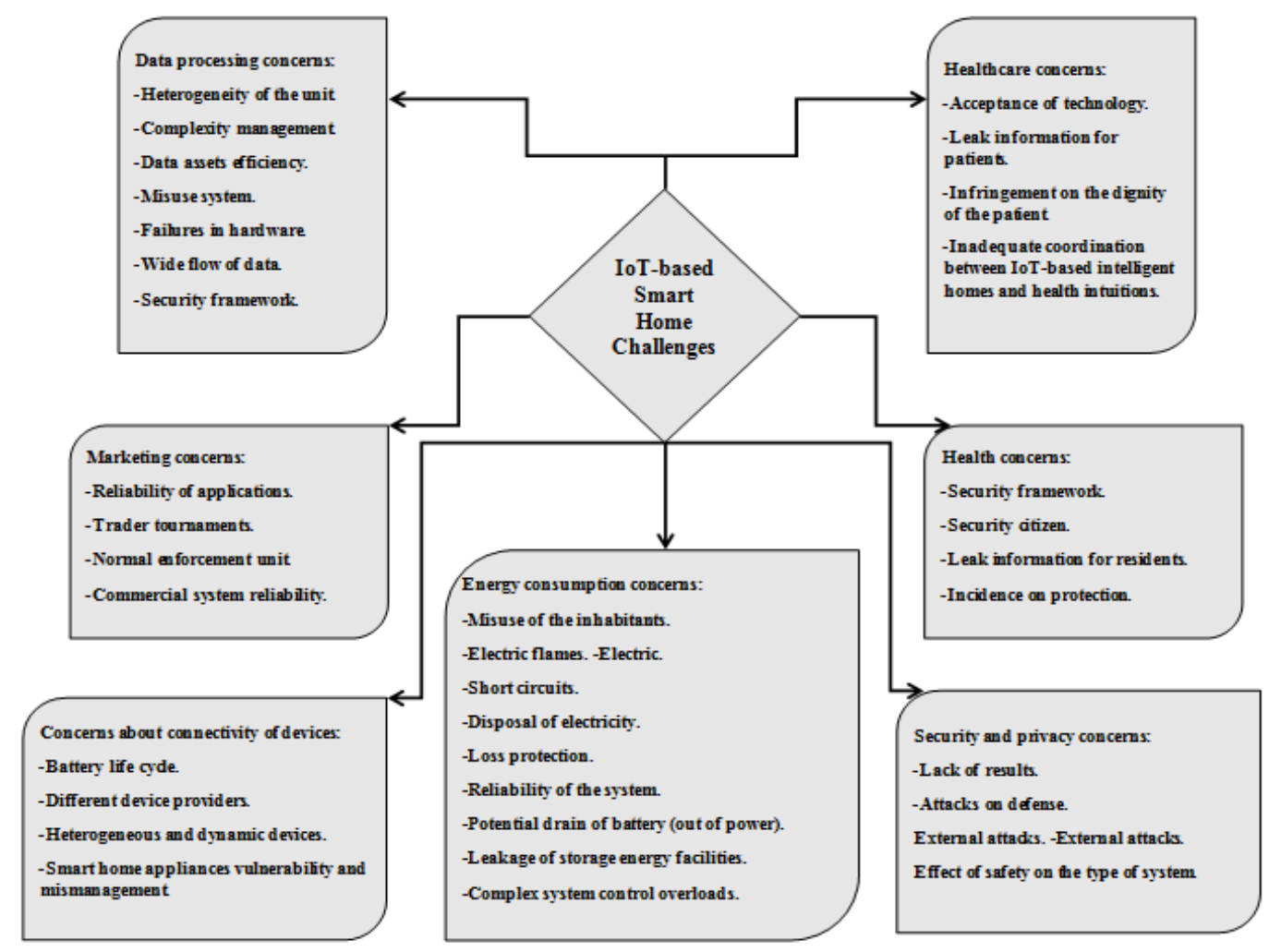

Figure 4. Challenges groups based on IoT intelligent home app methodologies

\section{RECOMMENDATIONS}

This section summarizes the literature recommendations most relevant to mitigating challenges and promoting the safe and successful use of smart home technologies such as IoT-based devices and sensors. There are recommendations for the user in terms of behaviour, energy consumption and device breakdowns, and safety and security recommendations to protect against external attacks and the entry of hackers [49][51] in Figure 5 explains the recommendations that the user should observe in SH systems.

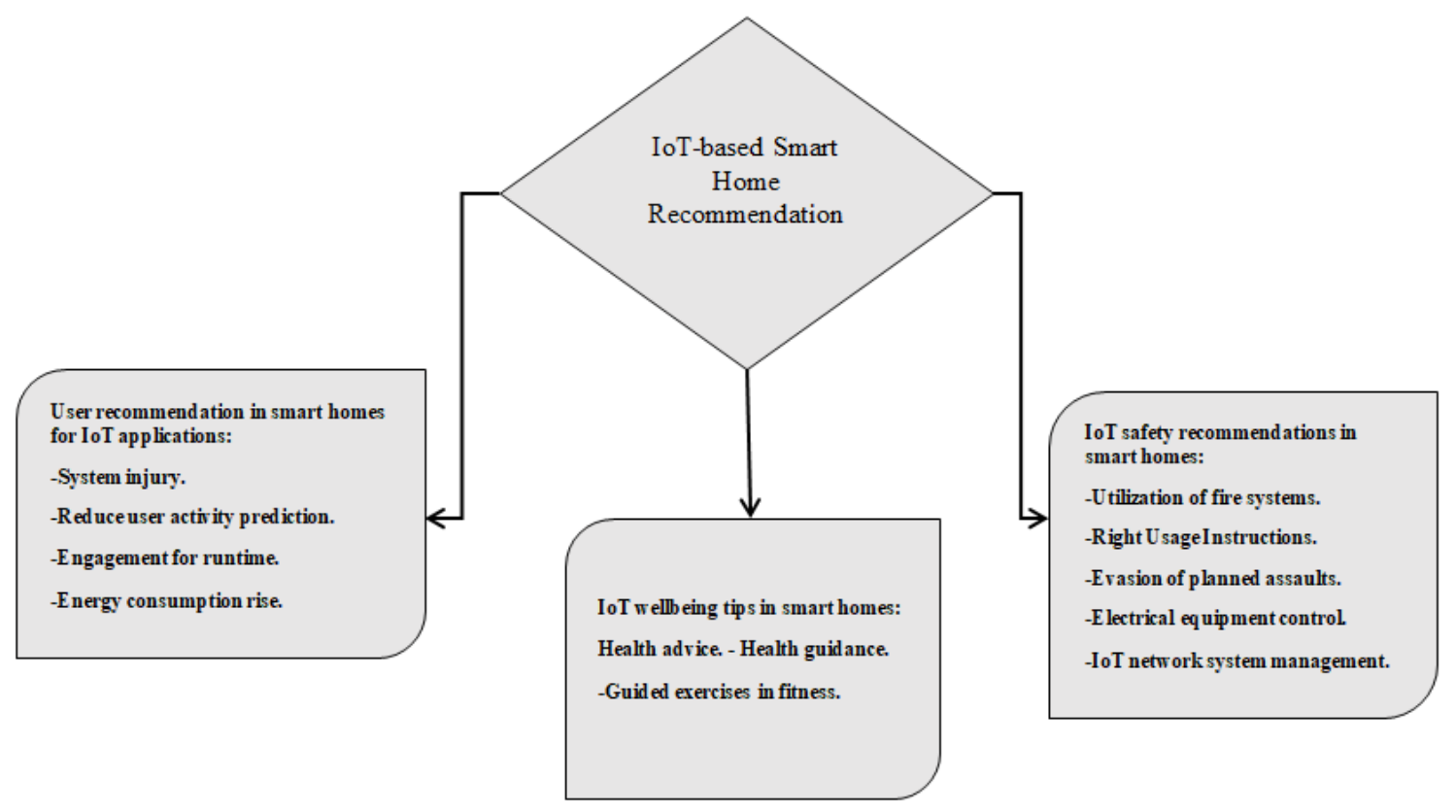

Figure 5. Recommendations groups for IoT applications in intelligent homes 


\section{CONCLUSION}

Recently, there has been a major emergence in the use of the intelligent process of Internet of Things applications in intelligent home technology. Although further research is being conducted, the descriptions and limitations associated with them continue to be ambiguous. This review paper focuses on the various studies of the IoT and intelligent systems, and what are the motivations that incentives us to study the smart home, in addition to discussing a different type of challenges facing smart homes, and finally, recommendations for increasing smart home application acceptance and use.

\section{REFERENCES}

[1] S. S. Sabry, N. A. Qarabash, and H. S. Obaid, "The road to the internet of things: A survey," in IEMECON 2019 9th Annual Information Technology, Electromechanical Engineering and Microelectronics Conference, Mar. 2019, pp. 290-296, doi: 10.1109/IEMECONX.2019.8876989.

[2] S. K. Y. Donzia, H. K. Kim, and B. Y. Shin, "Study on Cloud computing and Emergence of the Internet of the Thing in Industry," in NICS 2018 - Proceedings of 20185 th NAFOSTED Conference on Information and Computer Science, Jan. 2019, pp. 334-337, doi: 10.1109/NICS.2018.8606834.

[3] A. H. Ali, R. F. Chisab, and M. J. Mnati, "A smart monitoring and controlling for agricultural pumps using LoRa IOT technology," Indones. J. Electr. Eng. Comput. Sci., vol. 13, no. 1, pp. 286-292, 2019, doi: 10.11591/ijeecs.v13.i1.pp286-292.

[4] A. Zanella, N. Bui, A. Castellani, L. Vangelista, and M. Zorzi, "Internet of things for smart cities," IEEE Internet Things J., vol. 1, no. 1, pp. 22-32, Feb. 2014, doi: 10.1109/JIOT.2014.2306328.

[5] A. Mayub, Fahmizal, M. Shidiq, U. Y. Oktiawati, and N. R. Rosyid, "Implementation smart home using internet of things," TELKOMNIKA Telecommunication, Computing, Electronics and Control, vol. 17, no. 6, pp. 3126-3136, 2019, doi: 10.12928/TELKOMNIKA.v17i6.11722.

[6] J. L. Hernandez-Ramos et al., "Security and privacy in internet of things-enabled smart cities: Challenges and future directions," IEEE Secur. Priv., vol. 19, no. 1, pp. 12-23, 2021, doi: 10.1109/MSEC.2020.3012353.

[7] A. H. Omran, Y. M. Abid, A. S. Ahmed, H. Kadhim, and R. Jwad, "Maximizing the power of solar cells by using intelligent solar tracking system based on FPGA," in 2018 Advances in Science and Engineering Technology International Conferences, ASET 2018, Jun. 2018, pp. 1-5, doi: 10.1109/ICASET.2018.8376786.

[8] S. K. Vishwakarma, P. Upadhyaya, B. Kumari, and A. K. Mishra, "Smart Energy Efficient Home Automation System Using IoT,” Apr. 2019, doi: 10.1109/IoT-SIU.2019.8777607.

[9] A. H. Omran, Y. M. Abid, M. S. Mahdi, and A. Gh, "Design of intelligent controller to minimize the power consumption in smart city based on FPGA," 2020.

[10] E. Husni, G. B. Hertantyo, D. W. Wicaksono, F. C. Hasibuan, A. U. Rahayu, and M. A. Triawan, "Applied Internet of Things (IoT): Car monitoring system using IBM BlueMix," in Proceeding - 2016 International Seminar on Intelligent Technology and Its Application, ISITIA 2016: Recent Trends in Intelligent Computational Technologies for Sustainable Energy, Jan. 2017, pp. 417-422, doi: 10.1109/ISITIA.2016.7828696.

[11] F. Al-Turjman and J. P. Lemayian, "Intelligence, security, and vehicular sensor networks in internet of things (IoT)-enabled smart-cities: An overview," Comput. Electr. Eng., vol. 87, p. 106776, Oct. 2020, doi: 10.1016/j.compeleceng.2020.106776.

[12] N. A. J. Salih, I. J. Hasan, and N. I. Abdulkhaleq, "Design and implementation of a smart monitoring system for water quality of fish farms," Indones. J. Electr. Eng. Comput. Sci., vol. 14, no. 1, pp. 45-52, 2019, doi: 10.11591/ijeecs.v14.i1.pp45-52.

[13] M. Ayaz, M. Ammad-Uddin, Z. Sharif, A. Mansour, and E. H. M. Aggoune, "Internet-of-Things (IoT)-based smart agriculture: Toward making the fields talk," IEEE Access, vol. 7, pp. 129551-129583, 2019, doi: 10.1109/ACCESS.2019.2932609.

[14] N. P. Sastra and D. M. Wiharta, "Environmental monitoring as an IoT application in building smart campus of Universitas Udayana," in 2016 International Conference on Smart Green Technology in Electrical and Information Systems: Advancing Smart and Green Technology to Build Smart Society, ICSGTEIS 2016 - Proceedings, Mar. 2017, pp. 85-88, doi: 10.1109/ICSGTEIS.2016.7885771.

[15] G. Aceto, V. Persico, and A. Pescapé, "Industry 4.0 and Health: Internet of Things, Big Data, and Cloud Computing for Healthcare 4.0," Journal of Industrial Information Integration, vol. 18. Elsevier B.V., p. 100129, Jun. 01, 2020, doi: 10.1016/j.jii.2020.100129.

[16] A. H. Omran and Y. M. Abid, "Design of smart chess board that can predict the next position based on FPGA," Adv. Sci. Technol. Eng. Syst., vol. 3, no. 4, pp. 193-200, 2018, doi: 10.25046/aj030417.

[17] K. T. Kadhim, A. M. Alsahlany, S. M. Wadi, and H. T. Kadhum, "An Overview of Patient's Health Status Monitoring System Based on Internet of Things (IoT)," Wireless Personal Communications, vol. 114, no. 3. Springer, pp. 2235-2262, Oct. 01, 2020, doi: 10.1007/s11277-020-07474-0.

[18] M. R. Alam, M. B. I. Reaz, and M. A. M. Ali, “A review of smart homes - Past, present, and future," IEEE Trans. Syst. Man Cybern. Part C Appl. Rev., vol. 42, no. 6, pp. 1190-1203, 2012, doi: 10.1109/TSMCC.2012.2189204.

[19] S. J. Darby, "Smart technology in the home: time for more clarity," Building Research and Information, vol. 46, no. 1. Routledge, pp. 140-147, Jan. 02, 2018, doi: 10.1080/09613218.2017.1301707.

[20] B. L. Risteska Stojkoska and K. V. Trivodaliev, "A review of Internet of Things for smart home: Challenges and solutions," Journal of Cleaner Production, vol. 140. Elsevier Ltd, pp. 1454-1464, Jan. 01, 2017, doi: $10.1016 /$ j.jclepro.2016.10.006. 
[21] J. Y. Kim, H. J. Lee, J. Y. Son, and J. H. Park, "Smart home web of objects-based IoT management model and methods for home data mining," in 17th Asia-Pacific Network Operations and Management Symposium: Managing a Very Connected World, APNOMS 2015, Sep. 2015, pp. 327-331, doi: 10.1109/APNOMS.2015.7275448.

[22] O. Galinina, K. Mikhaylov, S. Andreev, A. Turlikov, and Y. Koucheryavy, "Smart home gateway system over Bluetooth low energy with wireless energy transfer capability," Eurasip J. Wirel. Commun. Netw., vol. 2015, no. 1, p. 178, Dec. 2015, doi: 10.1186/s13638-015-0393-3.

[23] B. Hamza, C. Ng, N. Noordin, M. F. A. Rasid, and A. Ismail, "Review of minimizing a vertical handover in a heterogeneous wireless network," IETE Technical Review (Institution of Electronics and Telecommunication Engineers, India), vol. 27, no. 2. pp. 97-106, Mar. 01, 2010, doi: 10.4103/0256-4602.60163.

[24] D. P. Acharjya and M. K. Geetha, "Internet of Things: Novel Advances and Envisioned Applications," vol. 25. Cham: Springer International Publishing, 2017.

[25] W. A. Jabbar, M. Ismail, R. Nordin, and S. Arif, "Power-efficient routing schemes for MANETs: a survey and open issues," Wirel. Networks, vol. 23, no. 6, pp. 1917-1952, Aug. 2017, doi: 10.1007/s11276-016-1263-6.

[26] N. David, A. Chima, A. Ugochukwu, and E. Obinna, "Design-of-a-Home-Automation-System-UsingArduino.doc," vol. 6, no. 6, pp. 795-801, 2015.

[27] U. Ozeer, L. Letondeur, F. G. Ottogalli, G. Salaun, and J. M. Vincent, "Designing and implementing resilient IoT applications in the fog: A smart home use case," in Proceedings of the 2019 22nd Conference on Innovation in Clouds, Internet and Networks and Workshops, ICIN 2019, Apr. 2019, pp. 230-232, doi: 10.1109/ICIN.2019.8685909.

[28] W. A. Jabbar, M. H. Alsibai, N. S. S. Amran, and S. K. Mahayadin, "Design and Implementation of IoT-Based Automation System for Smart Home,” Nov. 2018, doi: 10.1109/ISNCC.2018.8531006.

[29] B. Davidovic and A. Labus, "A smart home system based on sensor technology," Facta Univ. - Ser. Electron. Energ., vol. 29, no. 3, pp. 451-460, 2016, doi: 10.2298/fuee1603451d.

[30] R. K. Kodali and S. R. Soratkal, "MQTT based home automation system using ESP8266," 2016 IEEE Region 10 Humanitarian Technology Conference (R10-HTC), Apr. 2017, doi: 10.1109/R10-HTC.2016.7906845.

[31] D. M. Konidala, D. Kim, C. Yeob Yeun, and B. Lee, "Security Framework for RFID-based Applications in Smart Home Environment," J. Inf. Process. Syst., vol. 7, no. 1, 2011, doi: 10.3745/JIPS.2011.7.1.111.

[32] S. Badabaji, "An IoT Based Smart Home Service System," Int. J. Pure Appl. Math., vol. 119, no. 16, pp. 4659-4667, 2018.

[33] E. N. Ganesh, "Implementation of IOT Architecture for SMART HOME using GSM Technology," Int. J. Comput. Tech., vol. 4, no. 1, pp. 42-48, 2017, [Online]. Available: http://www.ijctjournal.org.

[34] O. Bhat, S. Bhat, and P. Gokhale, "Implementation of IoT in Smart Homes," Int. J. Adv. Res. Comput. Commun. Eng. ISO, vol. 3297, no. December, pp. 149-154, 2007, doi: 10.17148/IJARCCE.2017.61229.

[35] P. Gupta and J. Chhabra, "IoT based Smart Home design using power and security management," in 2016 1st International Conference on Innovation and Challenges in Cyber Security, ICICCS 2016, Aug. 2016, pp. 6-10, doi: 10.1109/ICICCS.2016.7542317.

[36] S. Kaur, R. Singh, N. Khairwal, and P. Jain, "Home Automation and Security System," Adv. Comput. Intell. An Int. J., vol. 3, no. 3, pp. 17-23, 2016, doi: 10.5121/acii.2016.3303.

[37] D. Mocrii, Y. Chen, and P. Musilek, "IoT-based smart homes: A review of system architecture, software, communications, privacy and security," Internet of Things, vol. 1-2, pp. 81-98, Sep. 2018, doi: $10.1016 /$ j.iot.2018.08.009.

[38] W. Keith Edwards and R. E. Grinter, "At home with ubiquitous computing: Seven challenges," Lect. Notes Comput. Sci. (including Subser. Lect. Notes Artif. Intell. Lect. Notes Bioinformatics), vol. 2201, pp. 256-272, 2001, doi: 10.1007/3-540-45427-6_22.

[39] M. Soliman, T. Abiodun, T. Hamouda, J. Zhou, and C. H. Lung, "Smart home: Integrating internet of things with web services and cloud computing," in Proceedings of the International Conference on Cloud Computing Technology and Science, CloudCom, 2013, vol. 2, pp. 317-320, doi: 10.1109/CloudCom.2013.155.

[40] D. J. Cook, A. S. Crandall, B. L. Thomas, and N. C. Krishnan, "CASAS: A smart home in a box," Computer (Long. Beach. Calif)., vol. 46, no. 7, pp. 62-69, 2013, doi: 10.1109/MC.2012.328.

[41] Y. Jie, J. Y. Pei, L. Jun, G. Yun, and X. Wei, "Smart home system based on IOT technologies," in Proceedings2013 International Conference on Computational and Information Sciences, ICCIS 2013, 2013, pp. 1789-1791, doi: 10.1109/ICCIS.2013.468.

[42] J. Hosek, P. Masek, D. Kovac, M. Ries, and F. Kröpfl, "IP home gateway as universal multi-purpose enabler for smart home services," Elektrotechnik und Informationstechnik, vol. 131, no. 4-5, pp. 123-128, Jul. 2014, doi: 10.1007/s00502-014-0209-x.

[43] S. Guoqiang, C. Yanming, Z. Chao, and Z. Yanxu, "Design and implementation of a smart IoT gateway," in Proceedings - 2013 IEEE International Conference on Green Computing and Communications and IEEE Internet of Things and IEEE Cyber, Physical and Social Computing, GreenCom-iThings-CPSCom 2013, 2013, pp. 720-723, doi: 10.1109/GreenCom-iThings-CPSCom.2013.130.

[44] T. Mendes, R. Godina, E. Rodrigues, J. Matias, and J. Catalão, "Smart Home Communication Technologies and Applications: Wireless Protocol Assessment for Home Area Network Resources," Energies, vol. 8, no. 7, pp. 7279-7311, Jul. 2015, doi: 10.3390/en8077279.

[45] M. Alaa, A. A. Zaidan, B. B. Zaidan, M. Talal, and M. L. M. Kiah, “A review of smart home applications based on Internet of Things," Journal of Network and Computer Applications, vol. 97. Academic Press, pp. 48-65, Nov. 01, 2017, doi: 10.1016/j.jnca.2017.08.017. 
[46] M. Khan, M. Toaha Raza Khan, and D. Kim, "Mitigating Interference and Energy Issues in Smart Homes Using Internet of Things," Apr. 2020, doi: 10.1109/WCNCW48565.2020.9124821.

[47] K. Maswadi, N. B. A. Ghani, and S. B. Hamid, "Systematic Literature Review of Smart Home Monitoring Technologies Based on IoT for the Elderly," IEEE Access, vol. 8, pp. 92244-92261, 2020, doi: 10.1109/ACCESS.2020.2992727.

[48] L. Y. Mano et al., "Exploiting IoT technologies for enhancing Health Smart Homes through patient identification and emotion recognition," Comput. Commun., vol. 89-90, pp. 178-190, Sep. 2016, doi: 10.1016/j.comcom.2016.03.010.

[49] A. A. Zaidan and B. B. Zaidan, "A review on intelligent process for smart home applications based on IoT: coherent taxonomy, motivation, open challenges, and recommendations," Artif. Intell. Rev., vol. 53, no. 1, pp. 141-165, Jan. 2020, doi: 10.1007/s10462-018-9648-9.

[50] S. Y. Y. Tun, S. Madanian, and F. Mirza, "Internet of things (IoT) applications for elderly care: a reflective review," Aging Clinical and Experimental Research. Springer, pp. 1-13, Apr. 10, 2020, doi: 10.1007/s40520-02001545-9.

[51] B. K. Sovacool and D. D. Furszyfer Del Rio, "Smart home technologies in Europe: A critical review of concepts, benefits, risks and policies," Renewable and Sustainable Energy Reviews, vol. 120. Elsevier Ltd, p. 109663, Mar. 01, 2020, doi: 10.1016/j.rser.2019.109663. 